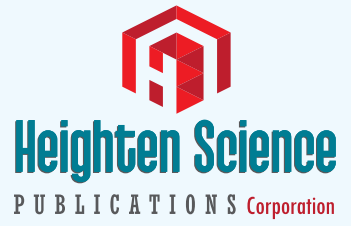

ISSN

2640-2890

Research Article

\title{
Screening of Gestational diabetes mellitus
}

\author{
Gehan Farid*, Sarah Rabie Ali* and Reem Mohammed Kamal \\ Department of Obstetrics and Gynecology Security Forces Hospital, Saudi Arabia
}

*Address for Correspondence: Dr.Gehan Farid, Department of Obstetrics and Gynecology Security Forces Hospital, Saudi Arabia, Email: Faridgi@yahoo.com

Sora Ali, Department of Obstetrics and Gynecology Security Forces Hospital, Saudi Arabia,Email: sora_ali@yahoo.com

\section{Submitted: 02 March 2018}

Approved: 03 April 2018

Published: 04 April 2018

Copyright: @ 2018 Farid G, et al. This is an open access article distributed under the Creative Commons Attribution License, which permits unrestricted use, distribution, and reproduction in any medium, provided the original work is properly cited

Check for updates

\section{Abstract}

Gestational diabetes mellitus is becoming a very common medical disorder associated with pregnancy especially so in the Middle East and more so in Saudi Arabia, thus putting the women and fetuses at an increased risk of maternal and neonatal morbidity and mortality.

Screening for Gestational diabetes mellitus was recommended because of its asymptomatic nature and good proportion of patients with no classic risk factors. We recommended universal screening because of the beneficial effect of screening, diagnosis and subsequent treatment.

The most recent study done in Security Forces Hospital showed a significant decrease in morbidity and mortality with application of the new values of screening, in spite of the increase of incidence of Gestational diabetes mellitus from $14.5 \%$ in 2005 study, to $23.9 \%$ in the recent study in 2015.

Objectives: To highlight and determine the best screening method values of FBS and $2 \mathrm{hrspp}$ used to diagnose gestational diabetes mellitus.

Maternal \& neonatal out come and associated risks for patients who had Gestational diabetes mellitus, where scrutinized.

The study was done in the period from June 1st 2013-31 of May 2014.

Design: Retrospective cohort study.

Setting: Tertiary centre (Security Forces hospital_Riyadh_Saudi Arabia).

Patients: Out of 6849 patients who had their delivery in Security Forces Hospital between June 2013 and May 2014 (one year), 6340 patients (92.5\%) were screened for gestational diabetes mellitus, and out of these 1516 patients $(23.9 \%)$ were labeled as Gestational diabetes mellitus after exclusion of cases of IDDM and NIDDM.

Main outcome measured: The purpose of this study is to advise on using new values for diagnosis of gestational diabetes and to assess the outcome of pregnancy after new values are implemented in security forces hospital for diagnosis. The outcome included ages of mothers, parities, number of abortions, associated medical disorders, and estimated blood loss. Control methods were also reviewed, gestational age of induction of labor. Associated intrapartum complications as well as fetal outcome were also reviewed. The weight of babies, congenital abnormalities, admission to neonatal intensive care unit were also studied. The different values used, and percentages of diagnosed values of last 3 studies done in Security Forces Hospital in comparison to the most recent study with new values(2014-2015) as shown in table 11.

Results: The incidence of gestational diabetes mellitus increased from $14.5 \%$ in the year 2003 - 2004 to reach $23.9 \%$ in 2014, in the same institute (Security Forces Hospital), where the study was done using different values. In our study in Security Forces Hospital we recorded a significant decrease in morbidity and mortality on applying the new values.

A significant reduction in the number of expired babies of mothers who were diagnosed as gestational diabetes with new values with a decrease from $5.6 \%$ in previous years studied to reach $1.5 \%$ in 2014 , reflecting the effective control and the good catch for the new values.

Conclusion: Universal screening, with whatever values to blood sugar used, is a better method screening than the selective one: Using 75 gram of Oral Glucose Tolerance Test proved to be cost effective, easily accessible, and with good pickup rate of up to $93 \%$ of patients in Security Forces Hospital.

Recommendations: To continue using the new values that will be universally implemented, with long term follow-up of mothers and newborn. 


\section{Introduction}

Gestational diabetes mellitus (GDM) is defined by glucose intolerance of variable severity with onset of first recognition during pregnancy [1]. Regardless if had preceded pregnancy, controlled by diet only or diet and insulin and disappeared after delivery. Hyperglycemia during pregnancy is found to be associated with various maternal and perinatal adverse outcomes [2,3]. Their offspring will have a life-long increase risk of glucose intolerance, obesity and metabolic syndrome whereas the mothers will have a higher risk of metabolic syndrome and diabetes in the future [4].

The detection of GDM during pregnancy provides an opportunity to identify women at risk of short term and long term complications. We now have evidence that early diagnosis and intervention can reduce the adverse perinatal outcomes [5-7]. Throughout the past years; there was no agreement on the most optimal diagnostic cut-off values to use until the most recent recommendation by the International Association of Diabetes and Pregnancy Study Groups (JADPSG) [8]. The purpose of this study is to advise on using new values for diagnosis and to assess the outcome of pregnancy after new values are implemented in security forces hospital for diagnosis.

\section{Material and Methods}

This is a cohort study done on a total number of 6849 patients who had their delivery in Security Forces Hospital in Riyadh, Saudi Arabia, between June 2013 and May 2014 (one year). Out of the 6340 patients screened for gestational diabetes mellitus, 1516 patients were labeled as gestational diabetes mellitus. 509 patients of these patients were excluded from the analysis as they escaped from screening for gestational diabetes mellitus.

The records of the study were reviewed by the help of the electronic system in the security forces hospital, in the form of medical records viewer were used to review the patients data, and to select the patients who positively screened patients, that were labeled as gestational diabetes mellitus.

Further antenatal sheets and the delivery data and outcome, as well neonatal complications were reviewed and followed up in pediatrician and neonatal intensive care unit notes, which include:

1. The patient characteristics include maternal age, height, weight, Parity, medical history, previous history of gestational diabetes mellitus, abortions, and gestational age at the time of delivery.

2. Delivery notes, whether spontaneous delivery or induced labor, any complications as post partum hemorrhage, perineal tear or lacerations, shoulder dystocia, and placental weight, and mode of delivery , instrumental or cesarean section were all reviewed.

3. Reviewed Neonatal notes including, weight, height, Head circumference, Apgar score, any anomalies, or any neonatal intensive care unit admission and the reason for that were studied.

\section{Results}

Analysis of patient's characteristics showed that the mean maternal age was 32.52 years, mean maternal weight was $77.23 \mathrm{~kg}$, and with a height of $155.7 \mathrm{~cm}$. Tables 1-3 shows that the percentage of prim gravida made of $16.4 \%$ of 248 patients, those with parity between 1 to 5 was $64 \%$,( 983 patients), and the parity between 6 to 10 was $16.3 \%$, (247 patients), and the percentage for 10 or more parity was $2.4 \%$, (37 patients). Hence most of the patients were with the parity between one and five. $62.5 \%$, (947 patients) of the patients had no history of GDM in previous pregnancies, versus $36 \%$ of patients, (546 patients, out of 947), with previous history of GDM in previous pregnancies. $38.9 \%$ of patients, (589 patients) gave history of previous miscarriages, 
Table 1: Show the values used by different authorities in different countries, internationally. So as to be able to compare with the values used in our study (2013-2014).

\begin{tabular}{|c|c|c|c|c|c|c|}
\hline & $\begin{array}{c}\text { Carpenter and } \\
\text { Coustan }\end{array}$ & ADA (2004) & ACOG (2011) & $\begin{array}{c}\text { WHO/NICE } \\
\text { (2008) }\end{array}$ & $\begin{array}{c}\text { RANZCOG } \\
(\mathbf{2 0 1 1})\end{array}$ & $\begin{array}{c}\text { JASPSG/ADA } \\
(\mathbf{2 0 1 2})\end{array}$ \\
\hline Fasting & $75 \mathrm{~g} \mathrm{OGTT}$ & $100 \mathrm{~g} \mathrm{OGTT}$ & $100 \mathrm{~g} \mathrm{OGTT}$ & $100 \mathrm{~g} \mathrm{OGTT}$ & $100 \mathrm{~g} \mathrm{OGTT}$ & $100 \mathrm{~g} \mathrm{OGTT}$ \\
1-h & $5.3 \mathrm{mmol} / \mathrm{l}$ & $5.3 \mathrm{mmol} / \mathrm{l}$ & $5.3 \mathrm{mmol} / \mathrm{l}$ & $7 \mathrm{mmol} / \mathrm{l}$ & $5.5 \mathrm{mmol} / \mathrm{l}$ & $5.1 \mathrm{mmol} / \mathrm{l}$ \\
& $10 \mathrm{mmol} / \mathrm{l}$ & $10 \mathrm{mmol} / \mathrm{l}$ & $10 \mathrm{mmol} / \mathrm{l}$ & - & - & $10 \mathrm{mmol} / \mathrm{l}$ \\
\hline 2-h & $8.6 \mathrm{mmol} / \mathrm{l}$ & $8.6 \mathrm{mmol} / \mathrm{l}$ & $8.6 \mathrm{mmol} / \mathrm{l}$ & $7.8 \mathrm{mmol} / \mathrm{l}$ & $8.0 / 9.0 \mathrm{mmol} / \mathrm{l}$ & $8.5 \mathrm{mmol} / \mathrm{l}$ \\
\hline $3-\mathrm{h}$ & $7.8 \mathrm{mmol} / \mathrm{l}$ & $7.8 \mathrm{mmol} / \mathrm{l}$ & $7.8 \mathrm{mmol} / \mathrm{l}$ & - & - & - \\
\hline
\end{tabular}

Table 2: Shows the patient characteristics of age, weight and height for 2013-2014 study.

\begin{tabular}{|c|c|c|c|}
\hline & N & Mean & Sed.Deviation \\
\hline Actual age & 1508 & 32.52 & 6.64 \\
\hline Maternal weight & 1497 & 77.23 & 16.37 \\
\hline Maternal height & 1485 & 155.7 & 6.16 \\
\hline
\end{tabular}

Table 3: Shows the percentage of parity, previous history of gestational diabetes mellitus and abortions.

\begin{tabular}{|c|c|c|}
\hline \multicolumn{1}{|c|}{ Parity } & Frequency & Percentage \\
\hline P0+0 & 248 & 16.4 \\
\hline $1-5$ & 983 & 64.8 \\
\hline $6-10$ & 247 & 16.3 \\
\hline$\geq 10$ & 37 & 2.4 \\
\hline Total & 1516 & 100.0 \\
\hline History of gestational diabetes mellitus & & 36.0 \\
\hline Yes & 546 & 62.5 \\
\hline No & 947 & 100.0 \\
\hline Total & 1516 & 38.9 \\
\hline Previous history of abortion & & 61.0 \\
\hline No & 589 & 100.0 \\
\hline
\end{tabular}

versus $61.0 \%$, (925 patients) with no such history of miscarry. Table 4 shows that the percentage of induced labor was $42 \%$ of patients, versus $58 \%$ were not induced, which means that more than half of the patients went into spontaneous delivery even if planned for induction of labor.

The percentage of term deliveries between 37 and 40 wks was $74.2 \%$, while preterm deliveries less than 37 wks was $7.1 \%$, and post term deliveries made up to $18.6 \%$ of patients, which means that most of the deliveries were term deliveries. It was observed that $70.5 \%$ of patients, had spontaneous vaginal delivery, versus $27 \%$ for cesarean section as mode of delivery, and $2.4 \%$ of patients had instrumental delivery, which means that most of the patients had vaginal deliveries. Most of the patients $(75.7 \%)$ were controlled on diet only, whereas $24.3 \%$ of patients were on diet and insulin as shown in table 5 , reflecting that most of the patients were well controlled by diet only.

$29.6 \%$ of patients had other associated medical disorders beside gestational diabetes in contrast to $70.2 \%$, which (1064 patients), who did not have other associated medical disorder.

As shown in table 6 that $58.9 \%$ of the patients didn't had any delivery complications versus $30 \%$, who had delivery complications, mainly in the form of vaginal lacerations. $5.7 \%$ of the patients had postpartum hemorrhage, and $2.7 \%$ of cases were complicated by shoulder dystocia. Hence the commonest complication was perineal tears, since the percentage of postpartum hemorrhage still remained within the acceptable percentage in terms of worldwide incidence. Also Estimated blood loss was found to be less than $500 \mathrm{cc}$ in $72.7 \%$ of the deliveries, compared to $27.3 \%$ with blood loss more than $500 \mathrm{cc}$. The number of hospital stay was (1-2 days) for $83 \%$ of the patients, $10 \%$ of the patients stayed (3-4 days), with $7 \%$ for 5 days or more. 
Table 4: Shows the percentage of induced pregnancies, its timing and mode of delivery.

\begin{tabular}{|c|c|c|}
\hline No of induced labor & frequency & percentage \\
\hline Induced & 635 & 42.0 \\
\hline Not induced & 881 & 58.0 \\
\hline Total & 1516 & 100.0 \\
\hline Weeks of delivery & & 7.1 \\
\hline$<37$ wks & 107 & 74.2 \\
\hline $37-40 w k s$ & 1125 & 18.6 \\
\hline$\varnothing \quad 40$ & 281 & 100.0 \\
\hline Total & 1516 & 70.5 \\
\hline Mode of delivery & & 27.0 \\
\hline Spontaneous vaginal delivery & 1069 & 2.40 \\
\hline Cesarean section & 410 & 100.0 \\
\hline Instrumental & 37 & \\
\hline Total & 1516 & \\
\hline
\end{tabular}

Table 5: Shows the type of control of gestational diabetes mellitus and other associated medical disorders.

\begin{tabular}{|c|c|c|}
\hline Type of Control & Frequency & Percentage \\
\hline Diet only & 1147 & 75.7 \\
\hline Diet + insulin & 369 & 24.3 \\
\hline Total & 1516 & 100 \\
\hline Other associated medical disorders & FREQUENCY & Percentage \\
\hline Yes & 448 & 29.6 \\
\hline No & 1064 & 70.2 \\
\hline Total & 1516 & 100 \\
\hline
\end{tabular}

Table 6: Shows the associated complications during labor, estimated blood \&hospital stay days.

\begin{tabular}{|c|c|c|}
\hline Maternal complications & Frequency & Percentage \\
\hline Postpartum hemorrhage & 86 & 5.7 \\
\hline Vaginal laceration & 454 & 2.7 \\
\hline Shoulder dystocia & 41 & 2.7 \\
\hline none & 49 & 100.0 \\
\hline Total & 1516 & 72.7 \\
\hline Estimated Blood loss & & 27.3 \\
\hline$<500$ c.c & 1102 & 100.0 \\
\hline$\geq 500$ c.c & 414 & 83.0 \\
\hline Total & 1516 & 10.0 \\
\hline Number of days & & 7.0 \\
\hline $1-2$ & 1260 & 100.0 \\
\hline
\end{tabular}

The Apgar score was more than 9 in 5 minutes in $70.7 \%$ of cases, versus $29.3 \%$ .Babies with Apgar Scores of 7 or more in 5 minutes as shown in table 7, hence reflecting good neonatal outcome. Only $12 \%$ had respiratory distress syndrome versus $88 \%$, who did not suffer from such a disorder. $6.5 \%$ out of the total number of the neonates was admitted to Neonatal intensive Care Unit. Out of all Neonatal intensive Care Unit admissions, $3.7 \%$ was for macrocosmic babies, ( 60 babies), and $1 \%$ had birth injuries (17 of the babies) and $6.3 \%$ of neonates had metabolic disorders (Tables 8,9). The percentages of congenital abnormalities was $9.5 \%$, (154 neonate), versus $91 \%$, and the percentage of still birth was $1.2 \%, 19$ neonate.

In Security Forces Hospital the percentage of screened patients increased significantly from 1993 where it was $60 \%$ (1993 to 1994), to reach $86.4 \%$ (19961997), and with further increase to $92.9 \%$ between (2003-2004), and with the value remaining at 92.5 (2013-2014) i.e. almost stationary (Table 10).

In a similar manner the percentage of diagnosed cases of GDM is increased to reach $23.9 \%$ in 2013 - 2014, in comparison to $14.5 \%$ in (2003-2004), and $9.3 \%$ in (19961997), and $5.9 \%$ in (1993-1994), (Table 11). 
Table 12 shows the percentages and comparison of cases admitted of delayed causes of administration to NICU in different years (1993-1994), (1996-1997), (2003-2004), and (2013 to 2014). It was found that the percentage of neonatal Hypoglycemia reached $3.3 \%$, (19 neonate), which showed that there is an increase in neonatal hypoglycemia, with new values used for screening of gestational diabetes mellitus. It was found that the other causes of delayed admission to neonatal intensive care unit like sepsis and asphyxia were $0.17 \%$, much less than previous years. The incidences of preterm were $6.45 \%$, and small for gestational age was $8.2 \% \& 12.2 \%$ for large for gestational age. The percentage of babies who had expired due to mothers with gestational diabetes mellitus showed a significant decrease to reach $1.5 \%$ in comparison to previous years, (Tables 12,13), which reflect the effectiveness of control by the use of new values.

Table 7: Shows the average Apgar score, percentage of Respiratory Distress Syndrome and Neonatal Intensive Care Unit admission.

\begin{tabular}{|c|c|c|}
\hline Apgar score & Frequency & Percentage \\
\hline$\geq 9$ & 1150 & 70.7 \\
\hline$\geq 7$ & 476 & 29.3 \\
\hline Total & 1626 & 100.0 \\
\hline Cases with Respiratory distress syndrome & Frequency & Percentage \\
\hline Yes & 199 & 12 \\
\hline No & 1427 & 88 \\
\hline Total & 1626 & 100.0 \\
\hline NICU admission & Frequency & Percentage \\
\hline Yes & 105 & 6.5 \\
\hline No & 1526 & 93.8 \\
\hline Total & 1626 & 100.0 \\
\hline
\end{tabular}

Table 8: Shows the percentage of Neonatal Intensive Care Unit admissions due to macrocosmic babies, injuries and metabolic disorders.

\begin{tabular}{|c|c|c|}
\hline Macrocosmic babies & Frequency & Percentage \\
\hline Yes & 60 & 3.7 \\
\hline No & 1566 & 96.01 \\
\hline Total & 1626 & 100.0 \\
\hline Due to injuries & 17 & 1.0 \\
\hline Yes & 1609 & 99.0 \\
\hline No & 1626 & 100.0 \\
\hline Total & & 6.3 \\
\hline Metabolic disorders & 101 & 93.7 \\
\hline Yes & 1525 & 100.0 \\
\hline No & 1626 & 6 \\
\hline Total & & \\
\hline
\end{tabular}

Table 9: Shows the percentages of congenital abnormalities and still births.

\begin{tabular}{|c|c|c|}
\hline Congenital abnormalities & Frequency & percentage \\
\hline yes & 154 & 9.5 \\
\hline No & 1472 & 91.0 \\
\hline Total & 1626 & 100.0 \\
\hline Still births & Frequency & percentage \\
\hline Yes & 19 & 1.2 \\
\hline No & 1607 & 98.0 \\
\hline Total & 1626 & 100.0 \\
\hline
\end{tabular}

Table 10: Shows the number of patients screened \& percentage of diagnosed cases of gestational diabetes mellitus in Security Forces Hospital.

\begin{tabular}{|c|c|c|c|c|}
\hline year & $\begin{array}{c}\text { Total No of patients } \\
\text { Screened }\end{array}$ & $\begin{array}{c}\text { Total No of } \\
\text { deliveries }\end{array}$ & $\begin{array}{c}\text { No of diagonal GDM } \\
\text { cases of GDM }\end{array}$ & Percentages \\
\hline $1993-1994$ & 3847 & 6411 & $383(5.9 \%)$ & 60.0 \\
\hline $1996-1997$ & 5619 & 6501 & $604(9.3 \%)$ & 86.4 \\
\hline $2003-2004$ & 5842 & 6282 & $917(14.5 \%)$ & 92.9 \\
\hline $2013-2014$ & 6340 & 6849 & $1516(23.9 \%)$ & 92.5 \\
\hline
\end{tabular}


Table 11: Illustrates the timing, values and outcomes of different screening values for GDM in Security Forces Hospital.

\begin{tabular}{|c|c|c|c|c|}
\hline Year & $\begin{array}{c}\text { Fasting blood } \\
\text { sugar } \\
\text { moml }\end{array}$ & $\begin{array}{l}2 \mathrm{hrs} \mathrm{pp} \\
\mathrm{mmol}\end{array}$ & $\begin{array}{l}\text { Number of diagnosed cases of Gestitional diabetes } \\
\text { Mellitus }\end{array}$ & Percentage \\
\hline June 93 - May94 & $\geq 5.8$ & $\geq 8.3$ & $5.9 \%$ & 60.0 \\
\hline June 96 - May97 & $\geq 5.6$ & $\geq 9.5$ & $9.3 \%$ & 64.0 \\
\hline Juneo4 - May 05 & $\geq 5.3$ & $\geq 7.8$ & $14.5 \%$ & 92.9 \\
\hline $\begin{array}{l}\text { June } 2013 \text { - May } \\
2014\end{array}$ & $\geq 5.1$ & $\geq 8.5$ & $23.9 \%$ & 92.5 \\
\hline
\end{tabular}

Table 12: Delayed causes of admission to Neonatal Intensive Care Unit.

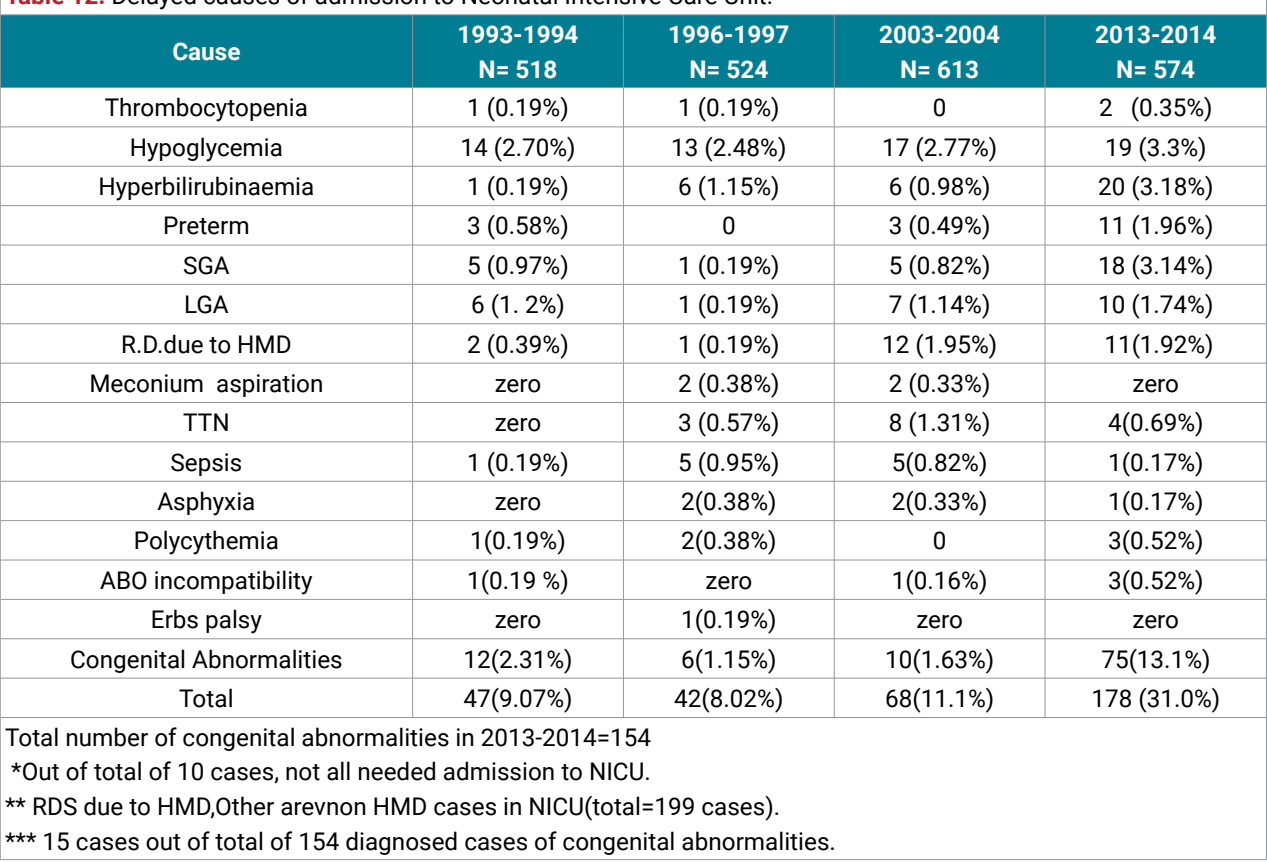

Table 13: Neonatal Intensive Care Unit. Admissions \& percentage of expiry in babies with Gestational Diabetes Miletus.

\begin{tabular}{|c|c|c|c|c|}
\hline Causes & $1993-1994$ & $1996-1997$ & $\mathbf{2 0 0 3 - 2 0 0 4}$ & $\mathbf{2 0 1 4 - 2 0 1 5}$ \\
\hline Total No of deliveries & 6411 & 6501 & 6282 & 6262 \\
\hline Total NICU admission & 518 & 524 & 613 & 574 \\
\hline Babies whose mother is GDM & $20(3.82 \%)$ & $34(8.82 \%)$ & $57(9.29 \%)$ & $78(31.0 \%)$ \\
\hline Total expired babies & $34(8.82 \%)$ & 52 & 47 & 67 \\
\hline expired babies of GDM mother & $0(0 \%)$ & $3(5.76 \%)$ & $3(6.38 \%)$ & $1(1.50 \%)$ \\
\hline
\end{tabular}

\section{Discussion}

Gestational diabetes mellitus is becoming a very common medical disorder associated with pregnancy especially so in the Middle East and more so in Saudi Arabia, thus putting the women and fetuses at an increased risk of maternal and neonatal morbidity and mortality. (GDM) defined as any degree of glucose intolerance with onset or first recognition during pregnancy. The definition applies whether insulin or only diet modification is used for treatment and whether or not the condition persists after pregnancy.

It doesn't exclude the possibility that unrecognized glucose intolerance may have antedated or begun concomitantly with the pregnancy. The incidence of gestational diabetes mellitus increased from 5.9\% in 1994 to reach $23.9 \%$ in 2014 in the institute where the study was done (Security Forces Hospital). During the period of study which compared the percentage of diagnosed patients of Gestational Diabetes Miletus in different years(1993-1994,1996-1997,2003-2004, and 2013-2014), the GDM rate increased persistently from $5.9 \%$ to $9.3 \%$ then $14.5 \%$ and to final study reached $23.9 \%$ respectively. 
The probable increase in rate may be due to the fact that security Forces Hospital became a Tertiary centre (in the year 2005) dealing with high risk cases and with transfer of low risk ones to a secondary hospital with which the hospital contracted in view of the increasing number of booked patients. Other causes of such increase in Gestational Diabetes Mellitus rate is due to increased number of pregnant patients screened due to increased awareness of the importance of screening. This increased percentage due to effective screening program in our hospital, and increased awareness about the medical disorder and associated complications in pregnancy, and reflects a good compliance of the pregnant ladies as well.

This increased incidence agrees with Gillman et al (20) where such increase was parallel to obesity of the patients \& was noted over past decade. The history of GDM dates back to 1964 when O"Sullivan proposed specific criteria to interpret the glucose tolerance level in pregnancy to identify women at a higher risk for developing diabetes after delivery [9]. The criteria was later modified by the National Diabetes Data Group(NDDG) in 1979 [10] and Carpenter and Coustan [11] due to the change from using venous whole blood samples to plasma or serum samples and technique used in analyzing blood glucose levels was also modified .

The Carpenter and Coustan diagnostic figures were lower than the NDDG criteria and therefore resulted in a higher prevalence of GDM. In 2000, the American Diabetes Association (ADA) recommended the use of the Carpenter and Coustan criteria for diagnosis of GDM. Despite this recommendation, various authorities in different counties and institutes had their own diagnostic threshold which resulted in a good deal of confusion between physicians, their patients, and lack of uniform agreement.

In 2008, the result of "Hyperglycemia and Adverse pregnancy Outcomes (HAPO)" study was published [2], and the aim of HAPO was to clarify any risks of adverse outcomes associated with a lesser degree of hyperglycemia and aid the development of an internationally agreed diagnostic criterion [2] of that study. 25,505 pregnant women were included from 15 centers in nine countries and tested by a 25g 2-hour OGTT between 24 to 32 weeks.

A continuous association was noted between glucose values and the likelihood of large for gestational age, primary caesarean delivery, fetal insulin levels and neonatal adiposity. In 2005, the Australian Carbohydrate Intolerance Study in Pregnant Women (ACHOIS) randomized 1000 women with diagnosed GDM using 75 g OGTT into intervention group and control group between 24 and 34 weeks of gestation. The rate of serious perinatal outcomes among infants decreased significantly from $4 \%$ to $1 \%$ after intervention.

Screening of Gestational Diabetes is a delicate matter, since the slightest deviation in the value can lead to different results which range from over diagnosis with increasing use of insulin beside diet\& further unnecessary diagnosis of gestational diabetes mellitus in contradistriction to the other side of the scale of under diagnosis if high values are used leading to fatal consequences of diabetes in pregnancy reflecting on the baby and the mother.

The method used should be adequate, timely, efficient, least expensive, and easy to implement, and prevent complication of Gestational Diabetes. Screening for GDM was recommended because of its asymptomatic nature and where almost half of patients had no classic risk factors. Screening before $24 \mathrm{wks}$ might miss GDM due to its path physiology of rising insulin resistance from second trimester. The widely adopted timing was between $24-28$ weeks, where timely intervention could potentially avoid the fetus being affected by maternal hyperglycemia. The methods of screening for Gestational Diabetes Mellitus could be performed by checking on the whole obstetric population (Universal Screening) or targeted pregnant with high risk factors (Called Selective Screening). (Universal Screening), was the method adopted in Security Forces Hospital since 2003 \& continued till 2016. 
In 2011, American College of Obstetrician and Gynecologists (ACOG), Royal Australian and New Zealand College of Obstetrician and Gynecologists (RANZCOG) recommended universal screening because of the beneficial effect from screening, diagnosis and subsequent treatment which further agrees with our method. The background of the population studied is important, where in areas with high incidence of type II diabetes mellitus, particularly in certain geographic areas like Gulf areas, Jordan, Iraq. etc..., amongest which is Saudi Arabia, where if selective screening was done rather than universal screening, then a good percentage of cases can be missed, since it was already mentioned that $50 \%$ of patients are asymptomatic \& without risk factors. The risk factors mentioned above include factors like advanced maternal age, high parity, obesity, polycystic ovarian syndrome (PCOS), multiple pregnancy, and family history of diabetes, obstetric history of congenital malformation, stillbirth, macrosomia and previous gestational diabetes mellitus, in addition to geographic locations already mentioned above.

The prevalence of Gestational Diabetes Mellitus is $5 \%$ in the United Kingdom, $3.7 \%$ in United States and 2-6\% among other European countries [13-15]. Higher prevalence of Gestational Diabetes Mellitus was noted in African, Asian, Indian and Hispanic women [17-19]. Generally the quoted prevalence of Gestational Diabetes Mellitus ranged from 2 to $23 \%$ worldwide [4], depending on the geographic area of the population being studied and the values used for screening for gestational diabetes [12]. If the $2 \mathrm{hrs}$ postprandial was high, above $9 \mathrm{mmol} / \mathrm{L}, 8 \%$ of cases will be missed. If only fasting blood sugar was used with values $\geq 4.8 \mathrm{mom} / \mathrm{L}$, only $70 \%$ of the population will be screened, and $10 \%$ will be missed.

The incidence of GDM $23.9 \%$ in our study seems to fall in the average of 1.1-25.5\% $[20,21]$, quoted for the United states after screening of different ethnic populations there. The values used in our study are those of IADPSG of the year 2010, and the literature published with the use of these figures \& outcome of Gestational Diabetes Mellitus is not much up to the present time. Looking on the already existing literature \& the values used in our study \& IADPSG, it was already published by Langer et al. [22], that fasting blood sugar of more than $\geq 5.3 \mathrm{moml} / \mathrm{L}$ was associated with large for gestational age infants, hence a less value was unrecompensed, and with our use of fasting blood sugar $\leq 5.3 \mathrm{moml} / \mathrm{L}$ in Security Forces Hospital, is a pointer that the values used are very reasonable and is in the right direction since the percentage of macrosoic babies \& hypoglycemic has decreased since 2005 where higher values of fasting blood sugar were used. The same argument also stands for the 2 hours postprandial of less than $7.0 \mathrm{moml} / \mathrm{L}$ used in blood sugar series.

The strength of our study is due to the long experience (over 15 years) in dealing with patients with gestational diabetes, in the same setting, national agreement on the values to use, a diabetic clinic being in the same day\& same place the endocrine team, with availability of diabetic educator and dietitians join the working with the team, hence uniformity of management, studies done and conclusions obtained. Perinatal mortality obtained in our studies was much less than the figures coated by Ramtoola et al. [23].

The increased number of diagnosed cases of congenital abnormalities is due to the uniform method of the running of the clinic, in addition to improvement in services in the ultrasound departments and especial training. In our study in Security Forces Hospital we recorded a significant decrease in morbidity and mortality for mother and newborn with application of the new values. A significant reduction in expired babies of mothers who were diagnosed as gestational diabetes with new values to decrease from $3 \%$ in 1996 to reach $1.5 \%$ in 2014, with the adopted new method of screening may help to explain this finding. The adopted policy of screening of delivered patients, six weeks after delivery, with care of the mother and newborn and regular frequent 
follow up in the concerned clinic, if the values were abnormal , in comparison to long term follow up of once a year (up to 3 years) if values are normal, seemed to help in raising the awareness of the public about the importance of screening for gestational diabetes, further it may help to reduce the number of patients who can convert to type ii diabetes, if no further care was adopted.

\section{Conclusion}

- The New screening method by using values of IADPSG, has resulted in increased number diagnosed cases of gestational diabetes. Further studies are still advised with this value.

- Special methods and timing of screening for areas with high background of diabetes suggested.

- Postpartum care by family medicine clinics, for both mother and newborn should be carried out on the target, patients with the diagnosis of GDM, and help draw future conclusion on the results\& help to prevent future development of type ii diabetes.

\section{References}

1. World Health Organization. Diabetes. 2012; 312.

2. HAPO Study Cooperative Research Group, Metzger BE, Lowe LP, Dyer AR, Trimble ER, et al Hyperglycemia and adverse pregnancy outcomes. N Engl J Med. 2008; 358: 1991-2002. Ref.: https://goo.gl/b5rtBD

3. Landon MB, Mele L, Spong CY, Carpenter MW, Ramin SM, et al. The relationship between maternal glycemia and perinatal outcome. Obstet Gynnecol. 2011; 117: 218-224. Ref.: https://goo.gl/bbWykA

4. American Diabetes Association. Gestational diabetes mellitus. Diabetes Care. 2004; 27: S88-S90.

5. Crowther CA, Hiller JE, Moss JR, McPhee Aj, Jeffries WS, et al. Effect of treatment of gestational diabetes mellitus on pregnancy outcomes. N Engl J Med. 2005; 352: 2477-2486. Ref.: https://goo.gl/16eVh8

6. Landon BM, Spong CY, Thom E, Carpenter MW, Ramin SM, et al. A multicenter, randomized trial of treatment for mild gestational diabetes. N Engl J Med. 2009; 361: 1339-1348. Ref.: https://goo.gl/3stxcB

7. Horvath K, Koch K, jeitler K, Matyas E, Bender R, et al. Effects of treatment in women with gestational diabetes mellitus: systematic review and meta-analysis. BMJ. 2010; 340: c2395. Ref.: https://goo.gl/zgNNJm

8. International Association of Diabetes and Pregnancy Study Groups Consensus Panel, Metzger IS, Gabbe SG, Persson B, Buchanan TA, et al. International association of diabetes and pregnancy study groups recommendations on the diagnosis and classification of hyperglycemia in pregnancy. Diabetes Care. 2010; 33: 676-682. Ref.: https://goo.gl/UDq73a

9. O"Sullivan JB, Mahan CM. Criteria for the oral glucose tolerance test in pregnancy. Diabetes. 1964; 13: 278-285. Ref.: https://goo.gl/JFTKTM

10. Classification and diagnosis of diabetes mellitus and other categories of glucose intolerance. National Diabetes Data Group. Diabetes. 1979; 28: 1039-1057. Ref.: https://goo.gl/q1vaa1

11. Carpenter MW, Coustan DR. Criteria for screening tests for gestational diabetes. Am J Obstet Gynecol. 1982; 144: 768-773. Ref.: https://goo.gl/WVhLfu

12. Agarwal MM, Dhattt GS, Punnose J, Koster G. Gestitional diabetes:dilemma caused by multiple international diagnostic criteria. Diabet Med. 2005; 22: 1731-1736. Ref.: https://goo.gl/NsM9E3

13. Diabetes in the UK 2010: Key statistics on diabetes. UK diabetes.

14. Buckley BS, HarreitervJ, Damm P, Corcoy R, Chico A, et al. Gestational diabetes mellitus in Europe:prevelance, current screening practice and barriers to screening. Diabet Med. 2011; 29: 844854. Ref.: https://goo.gl/E6Qir5

15. Kim SY, England L, Sappenfield W, Wilson HG, Bish CL, et al. Racial/Ethnic differences in thr percentage of gestational diabetes mellitus cases attributable to overweight and obesity, Florida, 2004-2007. Prev Chronic Dis. 2012; 9: E88. Ref.: https://goo.gl/QDDbdu 
16. Jenum AK, Morkrid, Sletner L, Vangen S, Torper JL, et al. Impact of ethnicity on gestational diabetes identified with the WHO and the modified international association of Diabetes and pregnancy Study Groups criteria: a population-based cohort study. Eur JEndocrinol. 2012; 166: 317-324. Ref.: https://goo.gl/92GUEH

17. Carolan M, Davey MA, Biro MA, Kealy M. Maternal age, ethnicity and gestational diabetes mellitus. Midwifery. 2012; 28: 778-783. Ref.: https://goo.gl/cK4z2X

18. Landon MB, Gabbe SG. Gestational diabetes mellitus. Obstet Gynecol. 2011; 118: 1379-1393.

19. Makgoba M, Savvidou MD, Steer PJ. An analysis of the interrelationship between maternal age, body mass index and racial origin in the development of gestational diabetes mellitus. BJOG. 2012; 119: 276-282. Ref.: https://goo.gl/gXZEdV

20. Gillman MW, Oakey H, Bayhurst PA, Volkmer RE, Robinson JS, et al. Effect of treatment of gestitional diabetes mellitus on obesity in the next generation. Diabetes Care. 2010, 33: 964-968. Ref.: https://goo.gl/igCZJH

21. National Diabetes Data Group. Diabetes in America. MD: National Institute of Health. 1995.

22. Langer O, Rodriguez DA, Xenakis EMJ, McFarland MB, Berkus, et al. Intesified versus conventional management of gestational diabetes. Am J Obestetric Gynecol. 1994; 170: 1036-1047. Ref.: https://goo.gl/yYMLws

23. Ramtoo la S, Home P, Damry H, Hasoona AH, Kiston S. Gestitional imparied glucose tolerance, does not increased perinatal mortality in a developing country: Short Study. BMJ. 2001; 322: 1025-1026. 